\title{
DE LA MEMORIA POPULAR A LAS AULAS: UNA PROPUESTA PARA LA FORMACIÓN LINGÜÍSTICA Y LITERARIA DEL PROFESORADO DE EDUCACIÓN INFANTIL Y PRIMARIA
}

\section{FROM THE PEOPLE'S MEMORY TO THE CLASSROOM: A PROJECT FOR LINGUISTIC AND LITERARY EDUCATION IN EARLY YEARS AND PRIMARY EDUCATION DEGREES}

http://dx.doi.org/10.15304/ie.28.4984

\author{
Estefanía Mosquera Castro \\ Universidade da Coruña \\ e.mosquera@udc.gal
}

Iria Sobrino Freire

Universidade da Coruña iria.sobrino@udc.es

Patricia Carballal Miñán

Universidade da Coruña patricia.carballal@udc.es

\author{
Ma Montserrat Muriano Rodríguez \\ Universidade da Coruña \\ montserrat.muriano@udc.es
}

\section{RESUMEN}

Nuestra propuesta surge de dos necesidades. Por una parte, poner en valor la literatura de tradición oral en el ámbito educativo y, por otra, reforzar las competencias lingüística y literaria del profesorado en formación. Con respecto a la primera de ellas, consideramos que, a pesar de que los géneros de tradición oral constan como contenidos del currículo, en la práctica es frecuente que sean obviados en favor de la literatura de autor. En cuanto a la segunda, hemos detectado que el alumnado de los grados de Educación Infantil y Primaria, en los que impartimos docencia, manifiesta bastantes dificultades para la expresión oral, especialmente en lengua gallega y, por otra parte, tampoco está familiarizado con las técnicas de narración oral. Por esta razón, hemos diseñado un proyecto que permite, de forma simultánea, darles respuesta: formamos al alumnado para que acudiese a centros educativos a contar cuentos de tradición oral y realizar una propuesta didáctica en relación con ellos. Dado el éxito de la 
actividad, decidimos ampliarla con el objetivo de que los futuros docentes tomen contacto también con las fuentes vivas de esta tradición, las personas de la tercera edad, que constituyen además el sector mayoritario que mantiene como lengua vehicular el gallego. Así, como fase previa a la visita a los centros educativos, los estudiantes acudieron a centros de día y/o residencias de la tercera edad para recopilar cuentos, leyendas, historias de vida, etc. Este material les sirvió de base para la propuesta didáctica que diseñaron y llevaron a la práctica en las escuelas.

Palabras clave: Aprendizaje-Servicio, formación del profesorado, educación literaria y lingüística, literatura de tradición oral

\begin{abstract}
Our proposal arises from two main needs we identified in Teacher Training programs: to enhance the value of traditional oral literature in education and to reinforce the linguistic and literary skills of future teachers. Regarding the former, our experience is that, even though the genres of traditional oral literature are included in the curriculum at different school levels, they are usually neglected in favour of written literature. In reference to the latter, we detected that our students have several problems with oral expression, particularly in the Galician language, and that they are not familiar with storytelling techniques. For that reason, we designed a project which simultaneously meets those needs: we trained students to design and carry out a teaching activity related to traditional oral literature in school classrooms. Given the success of this activity, we decided to expand it so future teachers could come into contact with the living sources of this tradition, the elders, who also keep the Galician language alive. Thus, prior to their visit to schools, the students go to day-care centres and/or elderly people's homes to compile folktales, legends, life stories, etc. These materials served as the basis for the teaching activity they designed and implemented at the schools.
\end{abstract}

Keywords: Service learning, teacher training, literary and linguistic education, traditional oral literature.

\title{
1. INTRODUCCIÓN
}

La propuesta educativa que se presenta está determinada, en principio, por las manifiestas carencias que hemos observado en dos ámbitos, relativos al manejo de las destrezas orales de las lenguas iniciales de nuestros alumnos y alumnas (gallego y castellano) y al escaso conocimiento que poseen de la literatura oral tradicional al comenzar su andadura universitaria.

En ambos casos, hemos observado que la formación lingüístico-literaria de nuestro estudiantado se ha articulado en torno a las manifestaciones y prácticas de la lengua escrita, en detrimento de la oralidad, evidenciando de este modo la clarificadora observación de Zumthor (1991):

en virtud de un prejuicio ya muy antiguo de nuestras mentes y que determina nuestros gustos, todo producto de las artes del lenguaje se identifica con la escritura; de ahí procede la dificultad que experimentamos para reconocer la validez de lo que no está escrito (p. 11).

En el caso de las lenguas, este prejuicio se ha traducido en el presumible abuso de paradigmas educativos tradicionales y gramaticalistas en las etapas anteriores de la formación lingüística de nuestro alumnado y que limitan el estudio de las lenguas al conocimiento de la morfosintaxis, la ortografía y el léxico de la lengua en sus variantes escritas (Cassany, Luna y Sanz, 1994) al tiempo que secundarizan 
la práctica de las destrezas orales a niveles anecdóticos. Esta orientación metodológica en la enseñanza de la L1, aunque profundamente reduccionista, se suele justificar con frecuencia por cuestiones pragmáticas, en la medida en que la parte comunicativa y funcional de las lenguas ya viene, en teoría, dada por el resto del entorno que rodea al alumnado, también el escolar pero fundamentalmente el familiar y el mediático (Mosquera Castro, 2015). No obstante, nuestra experiencia como docentes evidencia que la citada megafonía lingüística extraescolar no es suficiente, pues el alumnado manifiesta, incluso en los niveles universitarios, enormes dificultades para expresarse oralmente con fluidez y corrección y un bajo dominio de los recursos del discurso oral.

En el caso de la lengua gallega, la situación es todavía más preocupante, dado que en los últimos años se ha producido una acelerada pérdida de hablantes, especialmente alarmante en las nuevas generaciones (Freixeiro Mato, 2009). Esto redunda en una escasez de situaciones reales de comunicación en diferentes contextos, lo que parece haber determinado las carencias detectadas en cuanto a las habilidades lingüísticas orales de nuestro alumnado. Se trata, pues, de una realidad social con grandes implicaciones en la enseñanza y en la situación del gallego en ella. En este sentido, resulta evidente que hasta ahora no ha sido capaz de darle respuesta, como reflejan los datos ofrecidos por el Instituto Galego de Estatística (IGE) y como resultado de un marco legal de partida adverso (véase el Decreto 79/2010). Así, el 75\% de los menores de 15 años reconocen que hablan siempre o casi siempre en español al tiempo que el $22,7 \%$ afirma que sabe hablar poco o nada en gallego. Y esta realidad lingüística está presente en los niveles universitarios y, lo que es más alarmante, en grados de formación de profesorado. Por tanto, se trata de una necesidad que exige con urgencia una solución, en la medida en que será nuestro alumnado el profesorado encargado de formar a las próximas generaciones.

En consonancia con el prejuicio señalado por Zumthor (1991), hemos observado también que las nociones sobre la literatura oral por parte de nuestros alumnos y alumnas son, en la mayoría de las ocasiones, escasas o nulas. La histórica identificación entre literatura y cultura escrita ha originado que el canon escolar - cuyo estudio suele constituir la totalidad de la educación literaria que recibe nuestro estudiantado (Lomas, 2003) - obvie, en la mayoría de las ocasiones, las manifestaciones de la literatura oral (Carballal Miñán y Sobrino Freire, 2013).

Por otro lado, y a pesar de que en las últimas reformas educativas la enseñanza de la literatura oral está presente en los currículos de Educación Infantil y Educación Primaria -y también, aunque de forma menos significativa, en los pertenecientes a la ESO y Bachillerato-, creemos necesaria una revisión de estos contenidos - cuando menos en los currículos que rigen en Galicia- dado que parten de concepciones que no profundizan en las singularidades de la literatura oral. Así, tanto el Decreto 330/2009, de 4 de junio, por el que se establece el currículo de la Educación Infantil en la Comunidad Autónoma de Galicia, como el Decreto 105/2014 que establece el de Educación Primaria en la misma comunidad hablan de "lectura" y "memorización" de textos pertenecientes a los subgéneros de la literatura oral, obviando completamente tanto el fenómeno de la performance (Zumthor, 1991) como las nociones de variante y/o texto potencial que configuran estas manifestaciones y que posibilitan que los alumnos y alumnas no solo sean receptores, sino portadores y emisores idóneos de este tipo de literatura. 
La introducción de la cultura oral tradicional en la escuela viene siendo una demanda histórica por parte de algunos investigadores (Pelegrín, 1983; Reyzábal, 2001; Rodríguez Almodóvar, 2004; Pedrosa, 2008; Delgado Almansa, 2008; Cerrillo Toremocha y Sánchez Ortiz, 2012). Los estudios sobre didáctica de la literatura inciden en la importancia de que las criaturas accedan a este patrimonio, por su carga de afectividad, porque supone un vínculo con la cultura a la que pertenecen y porque les permite realizar una primera toma de contacto con la literatura, lo que les facilitará en el futuro el acceso a la lectura (Pelegrín, 2004). Además, este legado cultural supone muchos otros beneficios en la formación y socialización de los y niños y las niñas, como observa Pelegrín (2008): "Con la sabiduría decantada de la experiencia colectiva, el niño inicia lúdicamente aprendizajes múltiples: comportamientos, prácticas exploratorias, habilidades motrices, destrezas corporales, desafíos, riesgos, competiciones, ritmos. Complejas urdimbres, impulso vital del juego" (p. 11). En este sentido, también Cerrillo Torremocha (2003, 2004, 2006, 2011); Cerrillo Torremocha y Sánchez Ortiz (2012); Sánchez Ortiz (2008) y Rodríguez Almodóvar (1990, 2003, 2006) han insistido en la importancia del contacto temprano de los niños y niñas con este patrimonio para su desarrollo integral y su arraigo cultural.

Por todo ello, en esta propuesta, hemos querido hacer consciente al alumnado de la riqueza y la importancia de este tipo de cultura inmaterial - la literaria y también la lingüística- a la vez que facilitamos su acercamiento a los centros educativos de Educación Infantil y Educación Primaria para que sean ellos mismos quienes detecten y reviertan esta situación, sin perder de vista el lugar que en este proceso podrían ejercer otros colectivos, en tanto que muestra de responsabilidad social desde el ámbito universitario (Martínez Martín, 2008).

Nuestro enfoque pretende colocar las acciones comunicativas y dialógicas como centro de la enseñanza-aprendizaje, aunque no solamente para favorecer el intercambio lingüístico y así mejorar las competencias orales de nuestro alumnado, sino porque perseguimos que los descriptores que articulan las asignaturas pertenecientes a la didáctica de las lenguas iniciales y a la educación literaria sean programados y discutidos de forma conjunta para trabajar por un currículum democrático (Apple y Beane, 2000). De este modo, partimos del planteamiento de un problema inserto en la realidad social y cultural que rodea a nuestros y nuestras estudiantes para hacerlos partícipes en el diseño y configuración de actividades y propuestas educativas que avancen en su resolución (Beane, 2005, p. 76).

En este sentido, la metodología del aprendizaje-servicio (ApS) se constituye como "una combinación dual de aprendizaje académico y de servicio a la comunidad" (Deeley, 2016, p. 25) que permite que los y las discentes detecten y vivencien los problemas indicados por sí mismos a la vez que los reta a solucionarlos, reforzando así su confianza y su emancipación (Batlle, 2013).

Con nuestro planteamiento queremos alejarnos del pragmatismo de una educación lingüística y literaria de la formación de profesorado orientada meramente a la capacitación profesional, con el fin último de promover, en la medida de nuestras posibilidades, que nuestros estudiantes puedan convertirse en agentes activos para la educación y la ciudadanía crítica, mientras fomentamos las relaciones entre comunidad y universidad acentuando "el propósito público de la educación superior" (Deeley, 2016, p. 25). Se trata, de acuerdo con Gijón Casares (2009), de un tipo de propuesta que 
entiende las necesidades sociales como oportunidades para promover desafíos cívicos que pueden repercutir en la construcción de una sociedad más justa y solidaria. Esta autora considera además que cuando esas necesidades sociales no se resuelven generan un problema social que obliga a las instituciones a intervenir sobre esa realidad. Desde nuestra perspectiva como docentes, consideramos que el sistema educativo, y en especial el universitario, debe mirar críticamente a la realidad para ayudar a los jóvenes a involucrarse en los problemas y en las necesidades de la sociedad, dado que los formamos para integrarse con éxito en ella.

En consecuencia, nuestra propuesta centra su atención en varios aspectos que no funcionan y en situaciones de personas que sufren carencias. En primer lugar, cabe destacar como colectivos afectados al alumnado en edad formativa y a las personas de edad avanzada que, por diversas circunstancias, frecuentan centros de día o viven en residencias. El primero presenta notorias carencias formativas en relación con los aspectos anteriormente señalados en el primer apartado, mientras que en el caso del segundo estas son fundamentalmente afectivas y de reafirmación social: desarraigo, sentimiento de soledad, renuncia al entorno, pérdida de vínculos familiares, sociales y espaciales, vulnerabilidad, frustración, etc. (Mendía Gallardo, 1991).

En las últimas décadas se ha estado trabajando para paliar estos efectos negativos a través de la aportación de estímulos que incidan en la rehabilitación y la reactivación física y mental de este colectivo (véase, por ejemplo, Aparicio García-Molina, Carbonell-Baeza y Delgado Fernández, 2010); no obstante, nuestra propuesta de ApS entiende que, además de las carencias señaladas que conviene cubrir, ambos colectivos presentan fortalezas complementarias, motivo por el cual los dos son a la vez agentes y destinatarios del aprendizaje y del servicio. De acuerdo con Martín García (2009), este enfoque pedagógico aporta enormes beneficios en la construcción de un autoconcepto positivo por parte de ambos grupos, dado que -además de aumentar las relaciones personales e intergeneracionales- proporciona sentimientos de satisfacción y de responsabilidad, que contribuyen a un buen desarrollo de la autoestima.

\section{PROPUESTA DE APRENDIZAJE-SERVICIO}

A continuación, describimos pormenorizadamente la propuesta didáctica, integrada por dos proyectos de ApS que, si bien están íntimamente relacionados, como se puede comprobar, han sido llevados a cabo de forma individual por los distintos participantes involucrados, debido a la propia idiosincrasia de los grados (independientes y con contenidos y objetivos didácticos específicos) en los que se implementó.

\subsection{Levando a tradición oral á escola}

Este proyecto consiste en la realización de una propuesta didáctica alrededor de la literatura de tradición oral (cuentos, canciones, adivinanzas, trabalenguas, etc.) en aulas de Educación Infantil de entornos mayoritariamente castellano-hablantes. Las/los participantes son las alumnas y alumnos de 2. ${ }^{\circ}$ del Grado en Educación Infantil, dentro de la asignatura "Didáctica da lingua galega". Este proyecto, reconocido por la Universidade da Coruña como ApS en el Ámbito de la Responsabilidad Social Universitaria, comenzó a llevarse a cabo en el curso académico 2012/2013. 
Los objetivos del aprendizaje consisten, por una parte, en hacer consciente al profesorado en formación de la situación sociolingüística actual en los centros educativos urbanos y semiurbanos $\mathrm{y}$, por otra, en darle a conocer el patrimonio etnopoético, en particular con los cuentos, canciones y adivinanzas de tradición oral, en proporcionarle formación en técnicas de narración específicas para el público infantil y en ofrecerle la oportunidad de que diseñe y ponga en práctica una propuesta didáctica para un grupo de 2. ${ }^{\circ}$ ciclo de Educación Infantil. En el caso del alumnado no gallegohablante, otro objetivo del proyecto es contribuir a que adquiera fluidez en lengua gallega a través de una práctica útil y motivadora. En cuanto al servicio, sus objetivos son familiarizar a los niños y niñas de entornos castellano-hablantes con el gallego por medio de actividades lúdicas y ponerlos en contacto con la literatura de tradición oral.

Para determinar si los centros educativos son susceptibles de recibir el servicio, los grupos de estudiantes realizan una primera visita a las escuelas. Se dirigen a centros educativos situados en contextos predominantemente castellanófonos (la ciudad de A Coruña y ayuntamientos limítrofes). En esta visita llevan a cabo una observación del paisaje lingüístico del centro seleccionado y una entrevista tanto con la dirección del centro como con la tutora o tutor de aula de Educación Infantil, para obtener datos sobre: por un lado, la(s) lengua(s) habitual(es) en el centro, en el aula, entre el profesorado, el personal de administración y servicios y el alumnado; por otro, la utilización de la literatura de tradición oral en las actividades del aula. Los resultados suelen confirmar nuestras expectativas iniciales. En relación con la lengua, en el 100\% de los casos se verifica la necesidad de introducir o reforzar el uso del gallego en las aulas. Con respecto al empleo de literatura de tradición oral, el diagnóstico es semejante, pues solo en uno de los centros visitados hasta ahora se constató que se trabajaba con este repertorio (por lo que fue, consecuentemente, descartado).

El proyecto consta de las siguientes fases: formación, preparación, implementación y evaluación. La primera se compone de sesiones teóricas sobre el cuento y el cancionero infantil de tradición oral, lecturas y visionado de vídeos, talleres sobre cuento contado y literatura en la música tradicional y charlas con el alumnado egresado que ya participó en el proyecto en otros años. Esta fase tiene como objetivos principales, por un lado, conocer el patrimonio oral tradicional, comprenderlo en sus contextos de producción y reproducción y desterrar posibles prejuicios sobre él y, por otro, descubrir y practicar algunas técnicas de narración oral y baile tradicional. En primer lugar, las docentes ofrecemos una formación teórica introductoria en relación con los materiales de tradición oral. Con respecto al cuento, realizamos una selección previa de las recopilaciones de Harguindey y Barrio (1994), de Noia Campos (2002, 2010) y de la web Galicia Encantada, así como de las versiones de Antonio Reigosa y Xosé Miranda en la colección "Cabalo Buligán”, de Editorial Xerais. En relación con las canciones, adivinanzas y juegos de lengua, les proporcionamos recursos como la web Orella pendella, las recopilaciones de adivinanzas de Martín (1985) y de Arias Correa y Arias Correa (2008) o los libros-CD de Luís Prego (2013a y 2013b).

Además de las sesiones teóricas, esta fase se compone de talleres y charlas. En los últimos años hemos contado con la colaboración de los profesionales de la narración oral Raquel Queizás y Celso Fernández Sanmartín y del músico y bailarín Álvaro Abella Lage. De su mano, el alumnado ha podido aprender y practicar algunas de las técnicas que utilizarían después con los niños y niñas de Educación Infantil. Por otra parte, algunas exalumnas se han prestado también a colaborar con nosotras para orientar a sus compañeras y compañeros en la elaboración de su propuesta. 
La fase de preparación consiste, en primer lugar, en la selección de los materiales que van a servir de base para la propuesta didáctica. En grupos de 4 a 6 personas, el alumnado escoge un cuento y una canción, juego de lengua o adivinanza tradicional adaptados a las edades de los niños y niñas. A continuación, procede a diseñar una propuesta didáctica coherente para aplicar en el aula. Los grupos realizan los ensayos necesarios para la puesta en práctica, algunos de los cuales tienen lugar dentro del aula, en sesiones interactivas, con el propósito de que los compañeros y compañeras puedan aportar sugerencias y propuestas de mejora.

En la fase de implementación los estudiantes acuden a las escuelas y realizan su práctica con grupos de Educación Infantil. Estas sesiones son grabadas en vídeo para su posterior visionado y análisis en la facultad. Finalmente, en la fase de evaluación intervienen diversos agentes: el profesorado de los centros, los niños y niñas, las personas que imparten los talleres prácticos, los propios grupos, los compañeros y compañeras del aula universitaria y las profesoras de la asignatura. Posteriormente, el alumnado reflexiona por escrito sobre lo que supuso la experiencia para su formación. Los aprendizajes adquiridos se evalúan a través de un instrumento elaborado por las docentes, en el que se tienen en cuenta aspectos como la adaptación y oralización del cuento, la selección de los juegos de lengua, el empleo de una lengua de calidad y el fomento del uso del gallego en el alumnado de Educación Infantil.

\subsubsection{Resultados y propuestas de mejora}

Durante los seis cursos académicos en los que se lleva realizando esta experiencia, han participado en ella alrededor de 800 estudiantes, que han acudido a más de 75 aulas de Educación Infantil. A lo largo de estos años, hemos ido modificando la propuesta ${ }^{1}$ en función de los resultados obtenidos. Desde un repertorio inicial de cuentos bastante amplio y que reunía diversos tipos (maravillosos, de costumbres y de animales), nos hemos decantado últimamente por los cuentos de animales pues, debido a la sencillez de su estructura, son los que mejor se adaptan a las primeras edades. Al mismo tiempo, hemos ido comprobando la buena acogida que tienen piezas como las adivinanzas o los trabalenguas -a las que el alumnado de Educación Infantil parece no estar acostumbrado-, o aquellos juegos que aúnan lengua, movimiento y música. En relación con las técnicas de narración, tras experimentar con diversas propuestas (utilización de títeres, imágenes $\mathrm{u}$ objetos, técnica del narrador-mimador ${ }^{2}$, etc.), hemos optado por un tipo de narración basada en el trabajo de la voz y la expresión corporal, a partir del modelo de la commedia dell'arte $e^{3}$, en el que se otorga un peso especial a los diálogos entre los personajes y a su caracterización. Contados de este modo, incluso los cuentos con una cierta complejidad argumental (con engaños o ironía) se vuelven más comprensibles y atractivos para el público infantil.

Para una aproximación a los orígenes del proyecto, véase Sobrino-Freire (2012).

2 Narración entre dos personas, una de las cuales se encarga de contar la historia mientras que la otra representa a través del lenguaje corporal las acciones de los personajes.

3 Esta orientación se la debemos a la narradora y actriz Raquel Queizás (https://www.raquelqueizas.com/), que participa activamente en el diseño y evaluación del proyecto desde sus inicios. 
La propuesta también ha evolucionado para dar mayor cabida a la participación de los niños y niñas, tanto en la parte de los juegos de lengua como a través de una asamblea que se realiza después de los cuentos. El análisis de esta participación, junto con la observación y entrevista previos a la intervención, es lo que ha permitido a nuestro alumnado reflexionar sobre la realidad sociolingüística de los centros educativos gallegos de la ciudad de A Coruña y alrededores ${ }^{4}$. En este sentido constatamos un proceso emergente de concienciación sobre las necesidades de planificación lingüística en entornos castellano-hablantes, patente en comentarios como los siguientes:

esta experiencia nos ha servido para darnos cuenta de que nuestra lengua materna se está perdiendo por la poca importancia que se le da en las aulas a día de hoy por norma general. Sí es verdad que aunque que no la hablen [los niños y niñas] tienen el oído acostumbrado a esta lengua, pero fue curioso ver cómo interactuando con los niños en el aula en gallego ellos respondían en castellano

Pensamos que fue una experiencia más que enriquecedora, pero que debería dosificarse debido a la complejidad y carga de la actividad, pues pensamos que para que la lengua incida en las criaturas esta no solo debe darse un día de forma esporádica sino que debe ser un proceso gradual y lineal

En relación con la competencia lingüística del futuro profesorado, para el sector no gallegohablante la experiencia supone una oportunidad de practicar la lengua en contexto, aprender de los compañeros y compañeras que sí tienen el gallego como primera lengua, hacerse conscientes de los propios errores y autocorregirse. En el caso del estudiantado gallego-hablante el reto consiste en evitar los numerosos castellanismos léxicos incorporados a su lengua habitual ${ }^{5}$. Al reflexionar sobre esta experiencia, algunas personas resaltan su valor específico para el desarrollo de las habilidades lingüísticas: "Con este trabajo aprendí a hablar de forma más fluida y me sentí más segura con el gallego y sin miedo a equivocarme". Sin embargo, esta práctica no siempre logra el efecto deseado, pues al revisar las autoevaluaciones en ocasiones se observa un grado de satisfacción con su uso de la lengua que -comparado con nuestra percepción como docentes-podríamos calificar de "optimista" o de "autoindulgente". La concienciación sobre la necesaria calidad de la lengua del profesorado es, por tanto, uno de los aspectos en los que debemos seguir trabajando para reforzar en el futuro.

En las encuestas de evaluación que el alumnado cubre sobre la asignatura esta es siempre la actividad mejor valorada. De ella destacan tanto su dimensión de aprendizaje de competencias de la titulación como en la de servicio a la comunidad:

La intención de esta actividad era crear curiosidad por la lengua y por la tradición oral gallega en los niños y niñas, pero yo esto también lo he conseguido a nivel personal, [pues] despertó en mí mucho interés por estos relatos.

Por su parte, el profesorado de los centros educativos suele mostrarse en general satisfecho con los resultados de la experiencia, indicando que "los niños y niñas no estaban acostumbrados a este tipo de juegos de lengua, y menos en gallego", que las actividades son "útiles para tratar el

4 Para un análisis más pormenorizado de la potencialidad de este proyecto para la revitalización lingüística, véase DePalma, Zapico-Barbeito y Sobrino-Freire (2018).

5 Para un análisis de la competencia lingüística del futuro profesorado, véase Sobrino-Freire, DePalma y Zapico-Barbeito (2018). 
tema de la tradición oral gallega" y que los materiales de tradición oral suponen un enriquecimiento "cultural y social". Algunas docentes han alabado explícitamente el proyecto de ApS. No obstante, en algunos casos hemos percibido que la actitud lingüística de ciertos maestros y maestras no favorecía la realización de la actividad, pues en ocasiones interrumpían su desarrollo dirigiéndose a los niños y niñas en castellano -e incitándolos, consecuentemente, a que utilizasen esta lengua-. Estas situaciones, aunque no son las mayoritarias, nos hacen replantearnos el modo de selección de los centros.

Por último, desde nuestra perspectiva como docentes, creemos que este proyecto contribuye a la adquisición de las competencias y los objetivos de aprendizaje de la asignatura de un modo lúdico y motivador. En relación con la prestación del servicio, consideramos que tiene una potencialidad transformadora, pues potencia el uso de la lengua gallega en actividades asociadas al goce estético y al juego, lo cual incide en su normalización para el alumnado no gallego-hablante, cuya exposición a la lengua gallega suele ser escasa. Por otra parte, implica la puesta en valor y la revitalización de la cultura oral tradicional dentro de la escuela, en un ejercicio de compensación del proceso actual de ruptura de la transmisión intergeneracional de este patrimonio.

\subsection{Da memoria popular ás aulas}

Este segundo proyecto no solo mantiene los objetivos del primero -la puesta en valor de la literatura de tradición oral y la mejora de las destrezas orales en lengua gallega- sino que los amplía con la finalidad de que los futuros docentes mejoren también sus competencias orales en lengua castellana y de que accedan a los textos orales de voz de sus intérpretes para aproximarse, así, al proceso ontológico de la transmisión oral. En este sentido, se distingue del anterior, al que complementa, en varios aspectos. En primer lugar, está enfocado al alumnado de $1 .^{\circ}$ de Grado en Educación Primaria de la Universidade da Coruña. En segundo lugar, además de las fases ya señaladas en el punto 2.1. (formación, preparación, implementación y evaluación) se incluye una visita a los centros de día y/o residencias de la tercera edad con el objetivo de que los alumnos y alumnas, distribuidos en grupos de 4 a 6 personas, recopilen, a través de la interacción y el acompañamiento de las personas que allí se encuentran, muestras de literatura de tradición oral que les sirvan como material para la propuesta didáctica que tienen que diseñar. Por último, este segundo proyecto se ha elaborado con una proyección curricular distinta, ya que se ha desarrollado en dos materias universitarias a través del Tratamiento Integrado de Lenguas (TIL). Así, desde el curso académico 2016/2017 -en el que también fue reconocido por la Universidade da Coruña como ApS en el Ámbito de la Responsabilidad Social Universitaria- este proyecto se lleva a cabo tanto en la asignatura "Lingua galega e a súa didáctica" como en la materia "Lingua castelá e a súa didáctica".

$\mathrm{Al}$ igual que en la primera propuesta, ha existido una fase inicial de formación y, por tanto, de trabajo en el aula en el que, de forma coordinada, las docentes de las materias se han dedicado a familiarizar al alumnado con la literatura de tradición oral desde un punto de vista teórico-práctico. En concreto, en el curso 2016/2017 el alumnado ha recibido una sesión magistral a cargo de Antonio Reigosa, experto en cultura popular y literatura de tradición oral, que ha sido complementada con talleres de interpretación, prácticas de recopilación en el entorno y la preparación de un modelo 
de entrevista guiada $^{6}$ para realizar a los posibles informantes, consensuado entre las docentes y el alumnado. Asimismo, hemos facilitado a nuestros y nuestras discentes el acceso a varios materiales didácticos y recursos web como material complementario y de apoyo a todas las fases de la propuesta, como se detalla a continuación.

En todo momento, hemos priorizado que los recursos centrados en la literatura de transmisión oral fuesen transmitidos a nuestro alumnado a través de las nuevas tecnologías, ya que estas pueden recoger, en parte, algunas de las condiciones de la transmisión, como las que tienen que ver con la parte quinésica y paraverbal de los intérpretes. Así, además de recomendarles una guía digital orientativa sobre la literatura de tradición oral y sobre el proceso de recopilación y catalogación 7 , les presentamos diversos archivos de referencia que contienen este tipo de manifestaciones literarias, como la web Polafías de la sección de literatura oral de la Asociación de Escritores en Lingua Galega y Galicia encantada. Enciclopedia da Fantasía Popular de Galicia, entre otras de ámbito español y lusófono.

Más tarde, y gracias a la gestión de la Oficina de Cooperación e Voluntariado da Universidade da Coruña, hemos puesto en contacto a nuestro estudiantado con personas de edad avanzada, usuarias de centros de día, residencias del entorno y centros terapéuticos de nuestra ciudad. La elección de estas personas como informantes para la recopilación de literatura de tradición oral responde a diversas razones. En primer lugar, y en la línea de lo ya señalado en anteriores apartados, porque consideramos que es importante valorar su importancia como transmisores de conocimiento y, por tanto, concienciar al alumnado de su papel activo en la sociedad y en la cultura, abogando así por la necesidad de inclusión de este colectivo, muchas veces discriminado, en las prácticas educativas. De este modo, tal y como está articulada nuestra propuesta, contribuimos a fomentar las relaciones intergeneracionales y favorecemos la retroalimentación entre ellas (Zapico Barbeito, 2007a y 2007b). $\mathrm{Y}$ en segundo lugar, porque teniendo en cuenta la situación sociolingüística gallega, este colectivo concentra como fortalezas las carencias orales señaladas para el alumnado. De acuerdo con los datos estadísticos del IGE, en la actualidad solo el 31\% de la población de nuestra comunidad autónoma habla siempre en gallego y estos usos remiten principalmente para los grupos de edad más avanzada (Mosquera Castro, 2015). Asimismo, y dado el predominio abrumador de lo escrito en los últimos tiempos (MacLuhan, 2010), las personas mayores constituyen también un colectivo importante -aunque no el único- en tanto que fuentes vivas de la literatura de tradición oral que atesoran y transmiten valores culturales relevantes para las comunidades de las que forman parte. En todo caso, hemos dado cabida también a las manifestaciones orales emitidas en lengua castellana para priorizar el ya citado tratamiento integrado de lenguas y para contribuir a que nuestros alumnos y alumnas consideren y valoren el patrimonio oral de la literatura en las dos lenguas (Guash, 2008).

6 Este modelo incluía una ficha de cada informante que incorporaba datos como el nombre, la edad, la procedencia, la ocupación laboral y el tipo de escolaridad y una serie de preguntas sobre ítems clave que permitiesen aflorar la mayor cantidad de literatura de tradición oral, tales como los contextos en los que se producían esas historias (velatorios, labores del campo, etc.), las temáticas (miedo, muerte, etc.), las localizaciones (lugares con encantos, en los que hubiese un tesoro, etc.) o sus protagonistas (el hombre del saco, la Santa Compaña, etc. ).

7 Véase https://galiciaencantada.com/archivos/docs/lgtoral_Blanco_reigosa001.pdf 
A diferencia también del primer proyecto que hemos expuesto -y como ya ha sido referidodecidimos ampliar nuestro espectro de recogida a todas las manifestaciones de la literatura oral que nuestros discentes hayan podido recabar en sus encuentros con los colectivos de personas mayores, en un intento de que nuestro alumnado comprenda y valore el conjunto de la literatura oral. Así, nuestra propuesta no solo se ha basado en cuentos tradicionales sino que los alumnos y alumnas han recabado también otros subgéneros de la narrativa oral como las historias de vida y las leyendas (tradicionales o urbanas), además de textos poéticos de muy variada índole, a menudo intercalados con numerosos saberes del patrimonio oral inmaterial a veces ajenos a la propia literatura, pero de gran valor cultural para su formación cívica y cultural.

Tras el proceso de recogida que se llevó a cabo en los diferentes espacios señalados durante el mes de octubre de 2016, nuestros alumnos y alumnas entraron en una fase de clasificación de los textos de acuerdo con las características estructurales, enunciativas, funcionales y temáticas de los mismos. Esta fase se llevó a cabo en la materia "Lingua galega e a súa didáctica", en la que también realizaron una puesta en común de los materiales recopilados a través de un taller de interpretación oral.

Posteriormente, en la materia "Lingua castelá e a súa didáctica", el alumnado, dividido en grupos, seleccionó, adaptó y articuló una secuencia didáctica basada en la literatura oral recabada que fuese susceptible de ser implementada en los últimos destinatarios del proyecto: centros educativos que impartan el ciclo de Educación Primaria (especialmente aquellos que cuenten con un alto grado de exclusión social) y ONG de la ciudad de A Coruña que trabajan con niños y niñas de edades comprendidas entre los 6 y los 12 años $^{8}$. La implementación fue grabada en vídeo para que pudiera ser considerada en el aula con la presencia de las docentes y el resto del grupo.

En cuanto a la evaluación, conviene señalar que esta consta de varias fases y períodos. En primer lugar, aunque ambas docentes participen en todos los procesos, existen dos fases diferenciadas que se corresponden con los períodos de evaluación de cada materia, primer y segundo cuatrimestre respectivamente. Así, al final de la materia "Lingua galega e a súa didáctica" se evalúan las fases de recopilación y catalogación y al final de la asignatura "Lingua castelá e a súa didáctica" las fases de preparación e implementación. En ambos procesos contamos con la evaluación de los diferentes participantes del proyecto: así, en el caso de las visitas a centros de día y residencias los coordinadores de centro evalúan según sus criterios profesionales el resultado de la actividad y también se intentan recoger las consideraciones de los mayores. También se realiza una presentación en el aula en forma de "polafía", que sirve por un lado a las docentes como método de evaluación oral del alumnado y, por otro lado, que favorece que este realice su propia autoevaluación ${ }^{9}$. En el

8 Los alumnos y alumnas, divididos en grupos, debían escoger cualquiera de los textos orales recopilados (adivinanzas, canciones, leyendas, historias de vida o cuentos) para narrarlos, recitarlos y/o adaptarlos para los niños y niñas de los centros educativos y, posteriormente, realizar una breve secuencia didáctica a partir de ellos (que podía consistir en una breve puesta en común, una nueva recopilación de etnotextos similares en el aula o alguna actividad didáctica sobre estos). En todo momento, los/as estudiantes de grado debían resaltar el importante legado cultural que les habían transmitido las personas de la tercera edad.

9 Cada grupo entregó igualmente una memoria escrita en la que incluyeron información pertinente sobre los informantes, clasificaron la literatura de tradición oral recopilada y reflexionaron sobre las posibilidades didácticas del material recogido y sobre esta parte de la ApS. 
caso de la implementación de la propuesta didáctica, los docentes y/o responsables de los centros y los niños y niñas destinatarios aportan también su evaluación. Esta se complementa con el visionado en el aula de las diferentes propuestas, la evaluación de las docentes y la reflexión del alumnado de grado sobre las implicaciones de la $\mathrm{ApS}$ en su proceso de formación ${ }^{10}$; todo ello ofrece una visión de conjunto del proyecto que sirve en sí mismo de autoevaluación y que nos permite detectar y mejorar debilidades o carencias así como resaltar sus puntos fuertes.

\subsubsection{Resultados y propuestas de mejora}

Aunque este segundo proyecto tiene todavía poco recorrido -al menos si lo comparamos con el anterior- los resultados obtenidos en las diferentes fases de esta primera implementación nos permiten reflexionar tanto sobre los beneficios de la actividad como sobre modificaciones y mejoras de cara al futuro.

Así, vemos necesario que, en cursos venideros, nuestros discentes amplíen sus búsquedas de manifestaciones literarias orales a grupos de mayores que se encuentren fuera de la propia ciudad, y que pertenezcan a territorios rurales (que en principio habían sido descartados para facilitar la movilidad de nuestro alumnado). Esta variación obedecería a un intento por incrementar el corpus de textos literarios orales en lengua gallega, dado que el perfil de los usuarios y usuarias de los centros de día, organizaciones y residencias de mayores del entorno urbanita de A Coruña responde mayoritariamente a usos castellanohablantes. Además, permitiría que nuestro estudiantado reflexionase sobre la situación sociolingüística de su entorno con datos recabados de primera mano y obtenidos de sus propios intercambios lingüísticos.

Otras modificaciones, sin embargo, han sido llevadas a cabo a medida que se ejecutaba nuestra actividad. De este modo, si en un primer momento las docentes pensábamos que cada pequeño grupo de alumnos y alumnas debía ceñirse a las muestras por ellos recogidas para el diseño y la implementación de la propuesta didáctica, hemos desechado esta idea por inoperativa, dada la descompensación de materiales recogidos entre los diferentes grupos. Así, hemos optado por que la totalidad de alumnos y alumnas vertiesen sus datos en un corpus digital compartido con todos sus compañeros para favorecer el aprendizaje colaborativo y para que, a partir de él, elaborasen y articulasen sus propias secuencias didácticas.

También para futuros cursos contemplamos la posibilidad de abrir un espacio web cooperativo para colgar allí todo el material recopilado para toda la comunidad. De este modo, el corpus podría ir incrementándose curso a curso a la vez que colaboramos en la difusión de los textos y en la valorización de las personas mayores que participen como intérpretes. Esta misma línea de trabajo fue la que seguimos años atrás con otro proceso de recogida de cancionero tradicional infantil en el entorno familiar de nuestro alumnado, que fue vertido en el blog Arríncate cabalán! (Sobrino-Freire

10 Además de la presentación en el aula en la que debían exponer los vídeos, los grupos de alumnos/as entregaron una pequeña memoria en la que incluyeron los motivos de la elección del texto seleccionado, una breve explicación de la intervención en la clase del centro escogido y una pequeña reflexión sobre la experiencia y sus resultados. 
y Carballal Miñán, s.d.). Igualmente, sería muy interesante hacer también públicas las secuencias didácticas que se han implementado a partir de los textos recopilados para facilitar el trabajo docente de aquellas personas que deseen abordar estos aspectos en las aulas.

No obstante, la experiencia llevada a cabo hasta ahora ha ratificado nuestra creencia de considerar a las personas mayores como parte fundamental de la formación de nuestros discentes, que también ha calado en nuestro alumnado de grado, de acuerdo con las opiniones que nos han sido transmitidas una vez finalizado el período de recopilación. Asimismo, la buena acogida por parte de los dos colectivos implicados ha revalidado nuestra intención de poner en marcha nuevas dinámicas que contribuyan a incrementar los lazos emocionales ya creados entre nuestro alumnado y los usuarios y usuarias de los centros para continuar trabajando en el bienestar y la mejora del autoconcepto de estos últimos y en el sentido de responsabilidad social de los primeros.

Respecto a la puesta en práctica de las intervenciones didácticas de nuestros alumnos y alumnas en los centros educativos, es necesario destacar, en primer lugar, la cálida acogida de la propuesta por parte de los centros educativos receptores, que coinciden en relación a las necesidades detectadas y que consideran útiles y necesarias acciones como las que esta experiencia contempla. E independientemente de los resultados concretos de cada una de las intervenciones, consideramos que esta ApS ofrece a nuestro alumnado diversos beneficios: por un lado, permite poner en contacto al estudiantado universitario de los primeros cursos de formación del profesorado con sus futuros alumnos y alumnas. Por otro lado, los incita a mejorar su competencia lingüística y literaria como consecuencia del mayor nivel de responsabilidad social que les otorgan este tipo de acciones. En síntesis, porque con su intervención coadyuvan como agentes en la mejora de una necesidad educativa, lo que aumenta su motivación y su grado de compromiso.

El gran número de alumnado universitario implicado y el espacio temporal reducido para realizar las gestiones oportunas han impedido que en esta primera edición se haya podido implementar la propuesta en ONG que trabajan con un perfil de alumnado que presenta un alto grado de exclusión social (refugiados, emigrantes o personas de etnias como la gitana). En ese sentido, esperamos y deseamos en próximos cursos contribuir -en la medida de lo posible- a mejorar su inclusión y a reforzar sus competencias lingüísticas y literarias.

\section{CONCLUSIONES}

La puesta en práctica de nuestras propuestas parece estar cumpliendo, por el momento, los objetivos que nos habíamos propuesto a nivel curricular. Así, los intercambios lingüísticos derivados de las propuestas, junto con el trabajo diario en las aulas, han repercutido en general en una mejora de las competencias orales de nuestros alumnos y alumnas, especialmente en lengua gallega, en donde han ganado sobre todo fluidez. En relación con las competencias orales en lengua castellana, el ejercicio de acudir a los centros educativos y de día los ha hecho también conscientes de la importancia de la escucha activa y les ha permitido practicar otros registros, más formales, a los que no están acostumbrados en su día a día. 
Asimismo, ellos y ellas han ido redescubriendo el importantísimo patrimonio etnopoético que les rodea a medida que lo revalorizan y se convierten, como docentes, en conscientes portadores y transmisores de un legado que resiste así la quiebra intergeneracional y se transmite a las nuevas generaciones de niños y niñas, que de este modo, se convierten también en receptores e intérpretes futuros de una importante parte de sus coordenadas culturales.

No obstante, nuestra iniciativa trasciende el espacio de las aulas y busca, en último caso, la potencialidad transformadora y empoderadora de la enseñanza de todos los protagonistas de los dos proyectos, desde el estudiantado y las docentes universitarias hasta los alumnos y alumnas de los centros de Educación Infantil y Primaria, sin olvidar, evidentemente a las personas mayores que frecuentan los centros de día y residencias que, generosa y desinteresadamente, han contribuido a educar a nuestros jóvenes. Creemos, con Machado (2004), que el acceso a la literatura es un derecho de todos los individuos y que los maestros y maestras son quienes deben garantizarlo. Pero debemos también considerar quiénes son los portadores de la literatura $\mathrm{y}$, por ende, de la cultura que llega a las aulas y reivindicar que en una sociedad democrática deben tener cabida no solo todas las expresiones culturales que la componen (y no solo las hegemónicas), sino también todos los individuos portadores de las mismas. Solo si contemplamos, en diálogo con las ideas expuestas por Nussbaum (2010), que "[t]odas las democracias modernas son sociedades cuyos integrantes presentan grandes diferencias en numerosos aspectos" (p. 29) y que nuestra sociedad se basa en la interdependencia entre personas, podremos comprender que las diferencias culturales y lingüísticas son la clave para construir tanto el pensamiento crítico como una educación que prepara, no solo para el trabajo sino para el ejercicio de la ciudadanía y para la propia vida.

\section{REFERENCIAS BIBLIOGRÁFICAS}

Aparicio García-Molina, V. A., Carbonell Baeza, A. y Delgado Fernández, M. (2010). Beneficios de la actividad física en personas mayores. Revista Internacional de Medicina y Ciencias de la Actividad Física y el Deporte, 10(40), pp. 556-576.

Apple, M. W. y Beane, J. A. (2000). Escuelas democráticas. Madrid: Morata.

Arias Correa, A. y Arias Correa, D. (2008). As adiviñas. Propostas para traballar coas adiviñas galegas. Vigo: Ir Indo.

Batlle, R. (2013). El aprendizaje-servicio en España: el contagio de una revolución pedagógica necesaria. Madrid: PPC.

Beane, J. A. (2005). La integración del currículum. Madrid: Morata.

Carballal Miñán, P. y Sobrino Freire, I. (2013): Arríncate, cabalán!, un blog colaborativo para recoger y estudiar el cancionero infantil tradicional. En Investigación de calidad para mejorar la educación. II Congreso Internacional Multidisciplinar de Investigación Educativa. Libro de comunicaciones. (s. 1. ): CIMIE.

Cassany, D., Luna, M. y Sanz, G. (1994): Enseñar lengua. Barcelona: Graó.

Cerrillo Torremocha, P. C. (2003). La infancia y el cancionero popular. CLIJ. Cuadernos de literatura infantil y juvenil, 157, pp. 26-32.

Cerrillo Torremocha, P. C. (2004). Memoria, oralidade e escritura. Sobre literatura oral e literatura escrita. Boletín Galego de Literatura, 44, pp. 7-29 
Cerrillo Torremocha, P. C. (2006). El cancionero infantil. Su aprovechamiento didáctico. CLIJ. Cuadernos de literatura infantil y juvenil, 195, pp. 15-24.

Cerrillo Torremocha, P. C. (2011). Literatura y juego: las canciones escenificadas infantiles. Alicante: Biblioteca Virtual Miguel de Cervantes. Disponible en http://www.cervantesvirtual.com/ nd/ark:/59851/bmcqz2v3. [Consulta: 07-11-2018].

Cerrillo Torremocha, P. C. y Sánchez Ortiz, C. (2012). De la oralidad a la escritura: Un camino de ida y vuelta en el Cancionero Popular Infantil. Olivar, 13 (18), pp. 317-342. Disponible en: http://www.memoria.fahce.unlp.edu.ar/art_revistas/pr.5837/pr.5837.pdf [Consulta: 07-112018].

Deeley, S. J. (2016). El aprendizaje-Servicio en educación superior. Teoría, práctica y perspectiva crítica. Madrid: Narcea Ediciones.

Delgado Almansa, M. C. (2008). A tradición oral: unha viaxe pola memoria nas aulas de secundaria. Revista Galega de Educación, 41, 38-42.

DePalma, R., Zapico-Barbeito, M. H. y Sobrino-Freire, I. (2018). Future teachers as agents of language revitalisation: the case of Galician early childhood education. Language, Culture and Curriculum, 31(3), 303-317, DOI: https://doi.org/10.1080/07908318.2018.1504402

Freixeiro Mato, X. R. (2009). Lingua galega e preconcepto. Revista Galega de Filoloxía, 10, pp. 115-144.

Gijón Casares, M. (2009). Aprendizaje servicio y necesidades sociales. En J. M. Puig Rovira (coord.), Aprendizaje servicio (ApS): educación y compromiso cívico (pp. 53-70). Barcelona: Graó.

Guasch, O. (2008). Reflexión interlingüística y enseñanza integrada de lenguas. El Tratamiento Integrado de las Lenguas. Número monográfico de la revista Textos de didáctica de la lengua y la literatura, 47, pp. 20-32.

Instituto Galego de Estatística (2014). Enquisa estrutural a fogares. Coñecemento e uso do galego. Disponible en: https://bit.ly/2PenSCn [Consulta: 06-11-2018].

Lomas, C. (2003). Aprender a comunicar(se) en las aulas. Ágora digital, 5.

Machado, A. M. (2004). Lectura, escuela y educación literaria. Madrid: Anaya.

MacLuhan, M. (2010). A Galaxia Gutenberg: a creación do home tipográfico. Santiago de Compostela: Servizo de Publicacións e Intercambio Científico.

Martín, P. (1985). ¿Que cousa é cousa? O libro das adiviñas. Vigo: Galaxia.

Martín García, X. (2009). La pedagogía del aprendizaje servicio. En J. M. Puig Rovira (coord.), Aprendizaje servicio (ApS): educación y compromiso cívico (pp. 107-126). Barcelona: Graó.

Harguindey, H. y Barrio, M. (1994). Antoloxía do conto popular galego. Vigo: Editorial Galaxia.

Martínez Martín, M. (ed.) (2008). Aprendizaje servicio y responsabilidad social de las universidades. Madrid: Ediciones Octaedro.

Mendía Gallardo, R. (1991). Animación sociocultural de la vida diaria en la tercera edad. Bilbao: Departamento de Trabajo y Seguridad Social del Gobierno Vasco.

Mosquera Castro, E. (2015). A formación do profesorado de lingua galega: perspectivas pedagóxicas e modelo lingüístico. Revista de Estudios e Investigación en Psicología y Educación, Extr., 6, pp. 12-16. DOI: https://doi.org/10.17979/reipe.2015.0.06.98

Noia Campos, C. (ed.) (2002). Contos galegos de tradición oral. Vigo: Nigratrea. 
Noia Campos, M. (2010). Catálogo tipolóxico do conto galego de tradición oral: clasificación, antoloxía e bibliografía. Vigo: Universidade de Vigo.

Nussbaum, M. (2010). Sin fines de lucro. Por qué la democracia necesita de las humanidades. Madrid- Buenos Aires: Katz Editores.

Pedrosa, J. M. (2008). A literatura, a literatura oral, o xogo. Revista Galega de Educación, 41, pp. 9-11.

Pelegrín, A. (1983). Folklore y literatura. Cuadernos de pedagogía, 101, pp. 66-68.

Pelegrín, A. (2004). La aventura de oír: cuentos tradicionales y literatura infantil. Madrid: Anaya.

Pelegrín, A (2008). Cada cual atienda a su juego. Alicante : Biblioteca Virtual Miguel de Cervantes. Disponible en http://www.cervantesvirtual.com/nd/ark:/59851/bmcsb4k1 [Consulta: 07/11/18].

Prego, L. (2013a). Para cantar e bailar. Pontevedra: Cumio.

Prego, L. (2013b). Xogos musicais. Pontevedra: Cumio.

Reyzábal, M. V. (2001). La comunicación oral y su didáctica. Madrid: La Muralla.

Rodríguez Almodóvar, A. (1990). Literatura infantil y folclore. El Urogallo, p. 54

Rodríguez Almodóvar, A. (2003). Del hueso de una aceituna: (o qué será eso de la poesía infantil). Alicante: Biblioteca Virtual Miguel de Cervantes. Disponible en: http://www.cervantesvirtual.com/nd/ark:/59851/bmc2b8v7 [Consulta 07/11/18].

Rodríguez Almodóvar, A. (2004). El texto infinito. Ensayos sobre el cuento popular. Madrid: Fundación Germán Sánchez Ruipérez.

Rodríguez Almodóvar, A. (2006). Los cuentos populares al rescate. Boletín Iberoamericano de Teatro para la Infancia y la Juventud, 7, pp. 15-27.

Sánchez Ortiz, C. (2008). La voz escrita. la función educativa en la lírica popular infantil. En P. Cerrillo y C. Sánchez Ortiz (coords.). La palabra y la memoria. Estudios sobre lírica popular infantil. Cuenca: Ediciones de la Universidad de Castilla la Mancha.

Sobrino-Freire, I. (2012). O obradoiro de contacontos na titulación de Educación Infantil. En A. Ambròs, J. Perera y M. M. Suárez. Didáctica de la llengua i la literatura. Experiències d'innovació docent a la universitat / Didáctica de la lengua y la literatura. Experiencias de innovación docente en la universidad (pp. 237-243). Barcelona: Institut de Ciències de l'Educació, Universitat de Barcelona.

Sobrino-Freire, I. y Carballal Miñán, P. (s. d.). Arríncate cabalán [Blog]. Disponible en: http://arrincatecabalan.blogspot.com/ [Consulta 09-11-2018].

Sobrino-Freire, I. DePalma, R. y Zapico-Barbeito, M. H. (2018). O futuro profesorado de Educación Infantil como modelo de lingua: análise de producións orais e percepcións da competencia lingüística en galego. En Díaz, M., Vaamonde, G., Varela, A., Cabeza, M. C., García-Miguel, J. M. y Ramallo, F. (eds.), Actas do XIII Congreso Internacional de Lingüística Xeral (pp. 854-861). Vigo: Universidade de Vigo. Disponible en: http://cilx2018.uvigo.gal/actas/resumos/661972.html [Consulta: 10-11-2018]

Zapico Barbeito, M. H. (2007a). Comunicación e maiores: unha reflexión calidoscópica para un universo calidoscópico. En L. Álvarez Pousa, J. Evans Pim y B. Kristensen (eds.). Comunicación e persoas maiores. Actas do Foro internacional (pp. 95-104). Santiago de Compostela: Colexio Profesional de Xornalistas de Galicia e Observatorio dos Medios de Galicia. 
Zapico Barbeito, M. H. (2007b). O binomio persoas maiores e libros de texto. A imaxe e concepto de vellez no currículum escolar. En L. Álvarez Pousa, J. Evans Pim y B. Kristensen (eds.). Comunicación e persoas maiores. Actas do Foro internacional (pp. 257-265). Santiago de Compostela: Colexio Profesional de Xornalistas de Galicia e Observatorio dos Medios de Galicia.

Zumthor, P. (1991). Introducción a la poesía oral. Madrid: Taurus. 